\title{
Price stabilization in the market for new issues*
}

\author{
Kathleen Weiss Hanley, A. Arun Kumar, and Paul J. Seguin \\ University of Michigan, Ann Arbor, MI 48109-1234, USA
}

Received March 1992, final version received November 1992

This study examines price stabilization in new equity issues. Stabili-ation truncates the distribution of post-issue prices at a floor price, lowering the risk of adverse price moves and hence, in a competitive dealer market, reducing the bid-ask spread. Using 1,523 NASDAQ-traded firmcommitment initial public offerings issued between 1982 and 1987, we find that spreads narrow when the market price is close to the offer price and stabilization is most likely. Moreover, significant negative returns are documented after the hypothesized termination of stabilizing activities, suggesting that stabilization, and its cessation, affect market prices.

Key words: Initial public offerings; Bid-ank spreads; Microst:isture; Options pricing

\section{Introduction}

The literature on initial public offerings (IPOs) focuses primarily on the pricing and trading behavior of new issues. This literature gerere 15 assumes that the eventual market determination of the intrinsic vaiue of ail IPO results from the unobstructed interaction of supply and demand. $\mathrm{V}$ tis ssumption is tenable for underpriced issues (those experiencing positive in:- '- returns), the price discovery process for overpriced issues can often be impeded by price stabilization.

Although stabilization refers to numerous practices, the dsfinition we use, from a 1940 Securities and Exchange Commission release, is the buying of a security for the limited purpose of preventing or retarding a decline in its open market price in order to facilitate its distribution to the public' [Securities

Correspondence to: Kathleen Weiss Hanley, School of Business Administration, University of Michigan, Ann Arbor, MI 48109-1234, USA.

*For valuable comments, the authors thank Kaushik Amin, Chris Barry, Hank Bessembinder, Bhagwan Chowdry, Craig Dunbar, Jim Hamilton, Wayne Mikkelson (the referee), Robert Miller, Margaret Monroe, Jeff Netter, Annette Poulsen, Richard Ruback (the editor), H. Nejat Seyhun, Douglas Skinner, and Michael Vetsuypens, as well as seminar participants of the Market Stracture and Regulation Group at the University of Michigan, the 1992 Western Finance Association meetings, and the 1992 Financial Management Association meetings. 
Exchange Act Release 2446 (1940)]. To absorb open market selling and prevent a drop in market prices, the underwriter of an offer enters a 'syndicate bid', usually at the issue price. If selling pressure is large enough to preclude buying the securities at the issue price, the underwriter may either decrease its bid to successively lower levels or cease its efforts at stabilization altogether. Given that such activities are capital-intensive and their duration is governed by regulation [discussed in section 2], the underwriter can engage in stabilization for only a short period of time.

In this paper, we examine a sample of 1,523 NASDAQ-traded firm-commitment initial public offerings of stock issued between 1982 and 1987. Although actual stabilizing purchases are not observable, we provide indireci evidence of the existence of market stabilization through the behavior of bid-ask spreads and prices. We find that bid-ask spreads are smaller for issues hypothesized to be most affected by stabilization. Furthermore, stabilized offers decline in value following the cessation of stabilization.

Our findings complement work on the market microstructure of public equity offerings. Although information on the timing or amount of stabilizing purchases has never been reported to the SEC, managing underwriters were required to inform the SEC if they engaged in stabilizing activities. Stoll (1976) and Hess and Frost (1982) use this information to examine the influence of stabilization on returns. Stoll (1976) finds that, for a sample of 50 new equity issues, stabilized issues underperform nonstabilized issues by $4.2 \%$ over tie firs: ten days of trading. However, this difference is insignificant. He concludes that '... stabilization appears to occur in response to falling prices and presumably in an attempt to shore them up. The evident lack of success of stabilization makes one wonder why it is engaged in' (p. 101).

Hess and Frost (1982) divide a sample of 152 seasoned utility equity issues into stabilized and nonstabilized offers. They find that stabilization has no price effect for fourteen days after the offer.

Miller and Reilly (1987) examine the return and spread behavior of IPOs over the first five days of trading. For their sample, they find that the relation of the spread and its determinants differs between overpriced and underpriced issues only on the first trading day. Their study, however, does not incorporate the influence of stabilization on market prices. Hegde and Miller (1989) examine 540 IPOs, and while their model 'does not explicitly account for underwriter stabilization', they find the direct effect of stabilization on spreads to be 'negligible' (p. 85). In contrast, Ruud (1992) finds that the distribution of IPO returns is consistent with the existence of stabilizing activities. She documents a similarity between thie statistical characteristics of simulated price-supported returns and actual returns data.

The remainder of tine peper is organized as follows. In section 2 , we provide background information on the regulation of stabilization. The testable implications of the effect of stabilization on bid-ask spreads and return behavior are 
presented in section 3. Section 4 describes the data and methods employed. In section 5, we examine whether stabilization is reflected in bid-ask spreads. We examine the imnact of the hypothesized cessation of stabilization on subsequent stock returns ' $;$ ction 6 . Section 7 concludes the paper.

\section{The regulation and economics of stabilization}

\subsection{Regulation of stabilization}

Section 9(a)(6) of the Securities Exchange Act of 1934 makes it unlawful to:

effect either alone or with one or more other persons any series of transactions for the purchase and/or sale of any security registered on a national exchange for the purpose of pegging, fixing, or stabilizing the price of such security in contravention of such rules and regulations as the Commission may prescribe as necessary or appropriate in the public interest or for the protection of investors. ${ }^{1}$

The SE "aticaris $y$ tom of fixed price security distribution' and that in the field of sighilizing it is faced with an existing condition, not a theory'. ${ }^{2}$ In 1955 , the comission adopted Rule 10b-7, which sets forth the guidelines regulating the stabilization activities of participants in an offering at the time of distribution. This rule requires that the intent of the underwriter and the syndicate to stabilize the issue be disclosed in the prospect: . When there is no existing market for the security, as is the case with initial public offerings, the only limitation on the initial stabilizing bid is that it cannot exceed either the offer price or the bid of the highest independent dealer. Once a stabilizing bid is entered, it may be maintained or reduced at any time, but may only be raised if the stabilizer has made no purchases for three successive business days. There is no time limit per se to stabilization, but the SEC has ruled as follows:

Rule 10b-7 contemplates stabilizing transactions with relatively brief time limits; therefore, the pegging and fixing of a price over an extended period in connection with a continuing offering violates the anti-manipulative provisions of the Exchange Act. ${ }^{3}$

${ }^{1}$ Securities Exchange Act of 1934 s 9(a)(6), 15 U.S.C. $\$ 781(a)(6)$ (1982).

${ }^{2}$ Stock Exchange Piactices, Report of the Committee on Banking and Currency, Senate Report No. 1455. 73d Congress, 2d Session (1934) 55.

${ }^{3}$ First Home Investment Corp. of Kansas, SEC 1971'70-71 CCH Dec. $\bullet 78,091$. 


\subsection{Economics of stabilization}

Stabilization attempts to smooth, mitigate, or even avoid short-run price declines. The underwriter of the offering may also believe that stabilization in the first few trading days can avert or mitigate price declines indefinitely, particularly if there is heavy selling during the first few days of trading and the distribution is not complete. Moreover, if a price drop is apportioned over a number of days, the perception of overpricing may be obscured by intervening market moves or informational shocks, thus concealing the overpricing from the undeiwriter s clients (both investors and issuers).

The SEC acknowledges that stabilization is a form of price manipulation. However, it is 'a negarive type of manipulation since it seeks to retard and not to creai: affirmative market movements'. ${ }^{4}$ The SEC argues that the success of firm-commitment underwritings depends on the ability of the underwriter to sell the securities at or near the offer price. : example, if the market price falls substantially below the offer price before the distribution is complete, inyestors will purchase shares in the open market; the underwriter would then be unable to sell the remaining shares $t$ the offer price. In the absence of stabilization, underwriters may be less willing to offer firm-commitment contracts which, in turn, may hinder the ability of firms to raise capital.

The SEC recognizes that investors might be harmed because stabilization artificially pegs the price of the securities and facilitates the distribution of overpriced securities to the public. However, the SEC argues that underwriters that engage in stabilization for the purposes of manipulation would suffer a loss in reputation and would thus be less able to underwrite securities in the future.

\section{Testable implications of the effect of stabilization}

Since information on stabilizing activities is no longer available, we examine the effect of stabilization using indirect measures. Like Ruud (1992), we argue that stabilization truncates the distribution of post-offering stock returns in the short run. In this study, we investigate the presence of stabilization by examining the effect of this distributional truncation on the bid-ask spread.

Numerous studies, including Copeland and Galai (1983), demonstrate that the width of the bid-ask spread for a stock is at least partially determined by the volatility of the underlying stock price process. One explanation for this relation is the 'inventory cost' explanation. Dealers who post firm bid-ask quotes buy at the bid and sell at the ask. Subsequent price moves expose dealers to two types of losses. First, if the price subsequently increases, dealers suffer opportunity losses by selling at an ask which turns out to be too low. Second, and of greater

\footnotetext{
${ }^{4}$ Securities Exchange Act Release 2446 (1940); italics from text.
} 
relevance to this study, if the price subsequently decreases, the dealers' inventory of shares declines in value, thus imposing losses.

Stabilizing activities ser $:-$ to reduce this second cost. If dealers believe that, at least in the short run, stabilizing activities will prevent the market price from falling below some floor price, then inventory losses due to price declines will be mitigated. For example, assume that a dealer posts a bid price of $\$ 10$, believing that there is a floor price of $\$ 9$ at which the stabilizer is willing to buy stock from all potential sellers (including the dealer). In this case, the maximum loss the dealer believes he will incur on shares purchased at his quoted bid is $\$ 1$. Assuming that the dealer market is competitive, this reduction in potential losses will be reflected in the cost of providing liquidity services, i.e., the bid-ask spread. The value of this truncation to the dealer, and thus the reduction in the width of the bid-ask spread, depends on a number of factors. One important component is the difference between the posted quote and the floor price, which represents the maximum inventory loss suffered by the dealer due to price declines. As this difference narrows, inventory losses are reduced, as are the costs of providing liquidity services. Therefore, holding other factors known to affect the width of the bid-ask spread constant, there should exist a positive relation between the width of the quoted bid-ask spread and the distance between the current posted quotes and the floor price.

Stabilization is also analogous to a 'protective put' in that it truncates losses at the floor price. Indeed, as outlined in the appendix, stabilization at a floor price can be viewed as a put option written by the stabilizer with a strike price equal to the floor price. As the value of this option increases, the dealer's potential losses decline. Again, with competition among dealers, this decline will be reflected in the bid-ask spread. Thus, all else equal, there should exist a negative relation between the width of the quoted bid-ask spread and the value of a put option with a strike price equal to the floor price.

Stabilization, by nature, is capital-intensive. Moreover, as was discussed in section 2, stabilizing activities must, by law, be terminaied once the distribution is complete. Stabilization, therefore, should last for only a short time. Hence, the positive relation between the width of the quoted bid-ask spread and the distance between the current posted quotes and the floor price, as well as the negative relation between the width of the quoted bid-ask spread and the value of the put option written by the stabilizer, should decay over time.

Finally, stabilization is effectively a form of legal price manipulation. Therefore, ending such activities allows the unobstructed forces of supply and demand to dictate fair market prices. Since stabilization only exists to retard price declines, those issues that have been stabilized should experience observable declines in market price once stabilization is discontinued. Note, however, that in order to observe post-statuilization price declines, the value of the stabilizer's bid must exceed the intrinsic value of the security when stabilization ends. In 
other words, stabilizers do not smooth price declines all the way to the 'true' market value.

\section{Data and methods}

\subsection{Data}

The initial sample contains all 2,758 firm-commitment initial public offers issued from January 1982 to September 1987 , identified from the Investment Dealers' Digest Corporate Database, which is also the source for the offer date, CUSIP identifier, and offer price. In order to ensure access to bid, ask, and volume data, we require that the firm be initi lly listed and traded on NASDAQ. In addition, the firm must have nonzero volunic on the day of the issue to ensure that offer and trading dates coincide. The final data set contains 1,523 IPOs.

Since we are interested in the effect of stabilization on the cost of dealers' services, we record the reported closing bid-ask spread from the Center for Research in Security Prices (CRSP) data fur each security in the sample for each of the first thirty trading days. For the 453 (1.0\% of the total) observations for which bid or ask data is not available, the spread is not computed and that day's observation is omitted. We measure the relative bid-ask spread as the closing bid-ask spread divided by the daily price of the security reported on CRSP.

To measure the marginal effect of price stabilization on quoted spreads, we control for other factors known to affect the bid-ask spread. Follow ir g Hegde and Miller (1989) and others, we model the relative spread as a function of trading volume, price, the number of market makcrs, and volatility. Consequently, we collect data from CRSP on daily share volume, the number of market makers, and the corresponding market price, measured as the bid-ask midpoint of the security. From this data, we construct a number of volatility estimates which are detailed below. If any of these variables are missing from CRSP, the firm is not included in the sample for that day.

\subsection{Method's}

We model the effect of stabilization on bid-ask spreads using a method that allows for variation over time in this variable. Since we hypothesize that the duration and intensity of stabilization activities will decay over time, we compute separate cross-sectional regressions for each day for days $1-30$, using the relative bid-ask spread as the dependent vuriable and factors known to affect the bid-ask spread as independent variables. This method is similar to that used by Ibbotson (1975), Miller and Reilly (1987), Hegde and Miller (1989), and Conrad and Niden (199i). Due to rnissing values, the number of observations used in any one regression ranges from 1,466 to 1,502 . 
Wc cstinate 30 separate cross-sectional regressions (one for each of the 30 event daiys) of the form:

$$
\begin{aligned}
& \ln \left(\text { Relative spread }_{j t}\right) \\
& =\alpha_{t}+\beta_{1 t} \ln \left(\text { Volume }_{j t}\right)+\beta_{2 t} \ln \left(\text { Number of market makers }_{j t}\right) \\
& \quad+\beta_{3 t} \ln \left(\text { Price }_{j t}\right)+\beta_{4 t} \ln \left(\text { Volatility }_{j t}\right) \\
& \quad+\beta_{5 t} \ln \left(\text { Stabilization proxy }_{j t}\right) .
\end{aligned}
$$

Each cross-sectional regression uses da a from each firm $j$.

Our regression results are essentially unchanged if we expand the window to 60 or 100 days or use a linear specification. We do not report the results from the linear specification since the residuals conform less with the as sumptions of OLS analysis. Since we use a $\log \log$ specification with price as an independent variable, the results are statistically identical whether absolute or relative spreads are the dependent variable.

The mean absolute return is $9.61 \%$ on event day $1,1.69 \%$ on event cay 10 , and $1.46 \%$ on event day 40 . We therefore estimate a volatility measure that accounts for event-time-related heteroskedasticity. Our measure of volatility is computed as follows:

$$
\begin{aligned}
& \text { Volatility }_{j t} \\
& = \begin{cases}\text { Standard deviation of returns on days } 1-11 & \text { if } t \leqslant 6, \\
\text { Standard devia ion of returns on days } t-5 \text { to } t+5 & \text { if } t>6 .\end{cases}
\end{aligned}
$$

This measure is a const int for the first six days aid a two-sided rolling estimate of the standard deviation oi returns from day 7 onwards. We also estimate volatility using the first 60 returas as well as returns from 61 through 120 days after the offer. If stabilization truncates the distribution and biases observed volatility downwards [Ruud (1992)], then calculating standard deviations using the latter measure should mitigate this bias. Regression resuits using these measures of variance remain essentialiy unchanged.

We estimate two proxies for the effect of stabilization on the bid-ask spread. The first proxy is the 'nearness' of the market price to the floor price, caiculated as $\ln$ (Closing bid price/Floor price). We initially assume that the floor price is the offer price, which is consistent with the maximum allowable stabilizing bid under Rule 10b-7.

Second, since the effect of stabilization can be modeled as a put option, we also estimate Black-Scholes European put option values as an alternative to the ratio of the bid price to the floor price. To use the Black-Scholes option pricing formula, it is necessary to specify the value of two parameters: $T$, the number of 
time periods until the option expires, and $\sigma^{2}$, the price volatility per periorl. Since our sample contains only NASDAQ firms, the closing quotes used here represent firm commitments to buy or sell with ne possibility of rebalancing an inventory position until markets reopen the next trading day. The appropriate variance is thus the close-to-open variance, which is not available on the CR.SP NASDAQ tapes. Consequently, we use the standard daily variance estimate. We report results using $T=1$, although our conclusions are unaffected by the choice of $T$. We also ajsune that the overnight risk-free rate is zero.

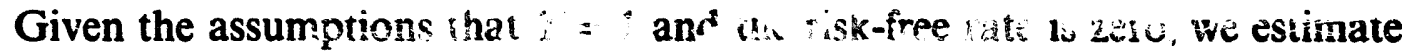

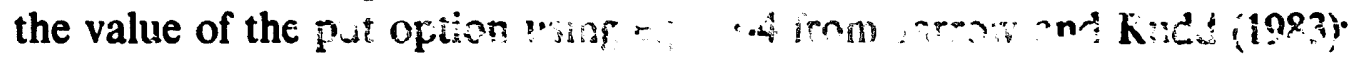

$$
\text { Put }=\text { Floor } * N(-d I) \ldots \text { nid price } * N(-d 2),
$$

where

$$
\begin{aligned}
& N(\cdot)=\text { Cumulative normal operator }, \\
& \because \quad=\left[\text { in(Bid price/Floor price) }+\sigma^{2} / 2\right] / \sigma, \\
& d i \quad=a i-\sigma,
\end{aligned}
$$

Floor $=$ Offer price .

\section{The effect of stabilization on bid-ask spreads}

\subsection{Relation of $\ln$ (Bid price/Offer price) to bid-ask spreads}

The first measure of potential stabilization is the log of the ratio of the closing bid price to the offer price, or the 'nearness' of the market price to the floor price. When this measure is large and positive, the current market price is above the hypothesized floor and the associated reduction in inventory losses attributable to the existence of stabilization is small. As this ratio approaches zero or turns negative, however, the floor price becomes a more relevant boundary and spreads s! : uld narrow.

Consequently, we examine the behavior of $\beta_{5 t}$, the estimate of the effect of In(Bid price/Offer price) on quoted spreads. If price stabilization exists and affects the bid-ask spread, then we expect that $\beta_{5 t}$ should be positive and that any significance of the relation should diminish over time.

Estimates of $\beta_{5 t}$ for each day over the first thirty days of trading are p'otted in fig. 1, with estimates significant at the $1 \%$ and $5 \%$ level highiighted. Consistent with our hypotheses, estimates of $\beta_{5 t}$ arc positive and significantly related to bid-ask spreads for tive first ten days of trading after controlling for volume, the number of market makers, the midpoint of the bid and ask prives, and volatility.

The observed pattern in the stabilization coefficient estima is is not due to shifts in the correlation structure of the independent variables over event time. Table 1 presents the regression results for each of the first ten irading days and in five-trading-day intervals thereafter. Only the volume coefficient changes in 


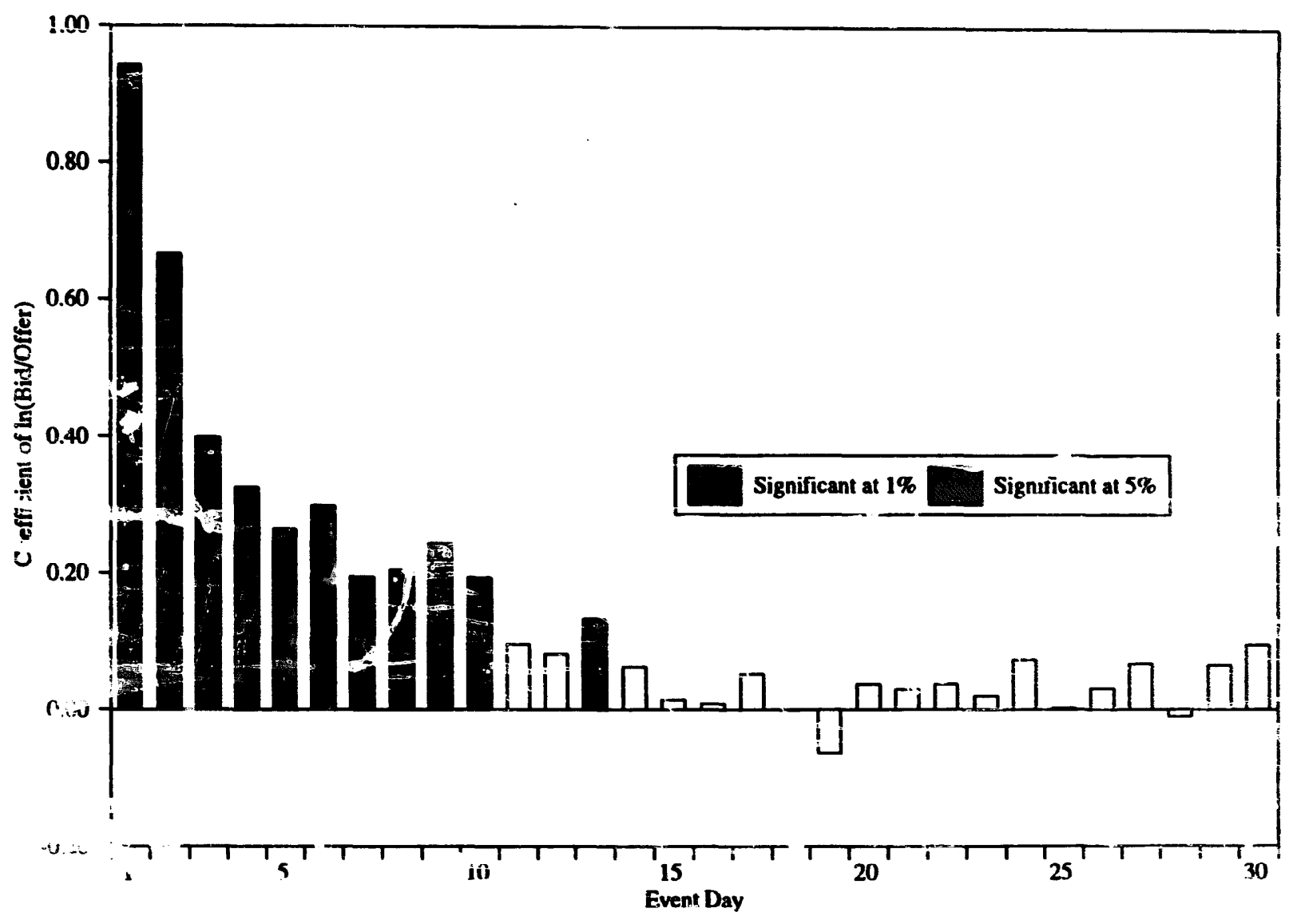

Flk. i. aic figure $p_{i}$ is estimates of $\beta_{5 t}$, the coefficient linking the width of the bid-ask spread to

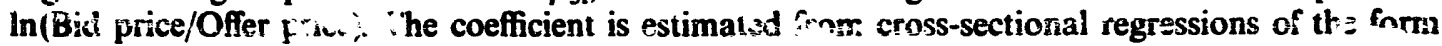

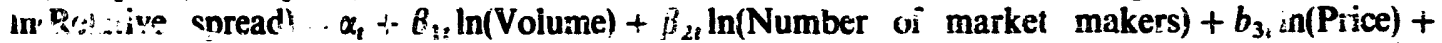
$\beta_{4}$ :niVoistility) $-f$ in standard dev $z^{\prime}$ io. $\cdots$, outed as ste standard deviation of daily retans of the first eleven days if the

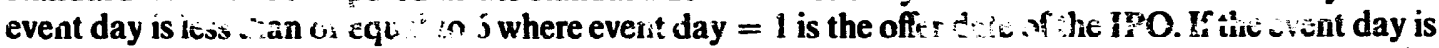
greater than 6 , then volatility $! s$ measured $\ldots$ s the standard d yiaticn of daily returns over the eleven-day window from five days before to five days after the event day. The sample consists of 1,523 IPOs on NASDAQ between 1982 and 1987, identified from Investment Dealers' Digest. The number of observations for each event day cross-sectional regression varies from 1,466 to 1,502. All data, wil? the exception of the offer price, are from the CRSP NASDAQ tapes.

event time, although the change in that coefficient is only weakly correlated with changes in $\beta_{5 t}$.

Since we use a $\log$-log specification, coefficient estimates are unit-free and can be interpreted as elasticities. Consequently, the magnitudes of the coefficients are related to the relative economic importance of the independent variables. Table 1 demonstrates that the largest elasticity over the first few days is associated with the statilization variable.

These results are uniformly consistent with the propositions that the relation between the width of the ibid-ask spread and the distance between posted quotes and the floor price is significantly positive and that this relation decays by day 10 . 


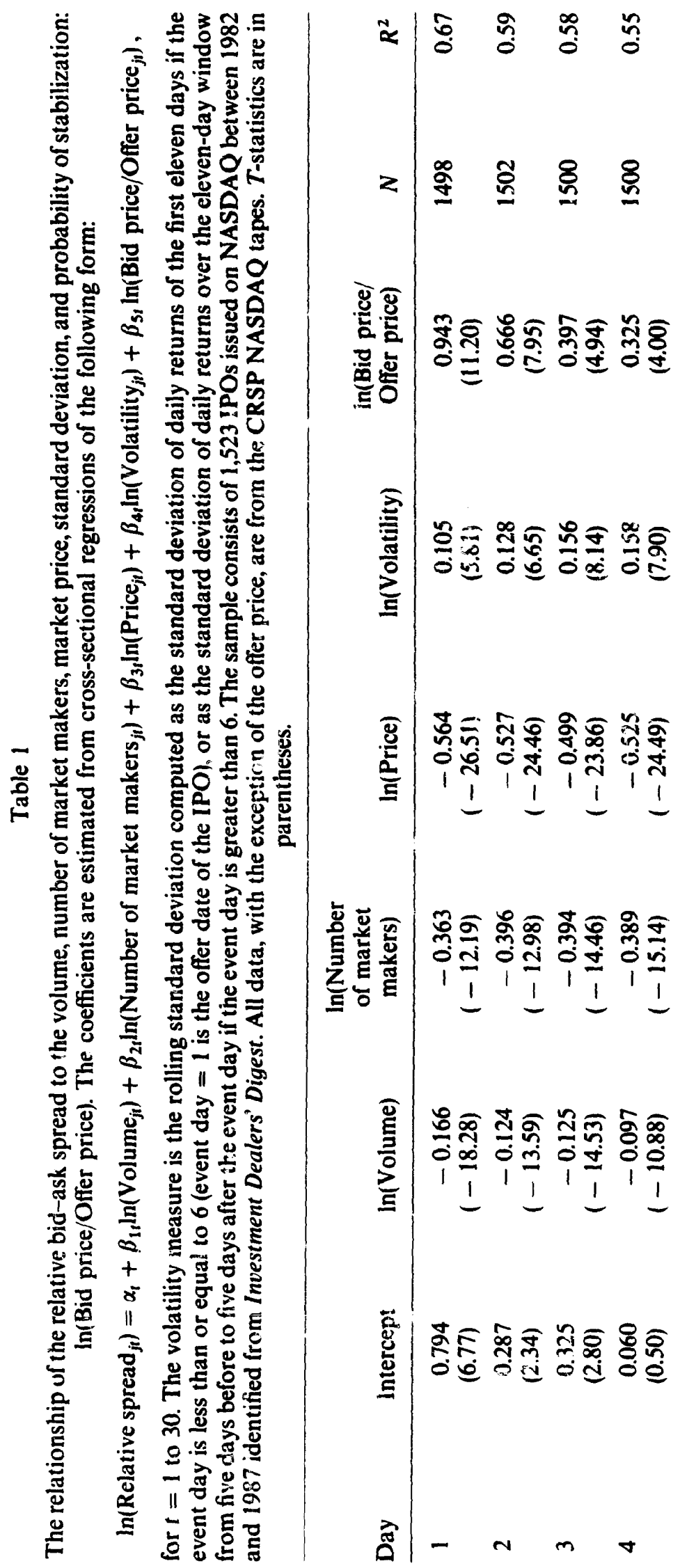




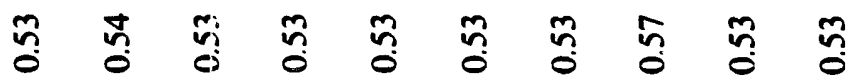

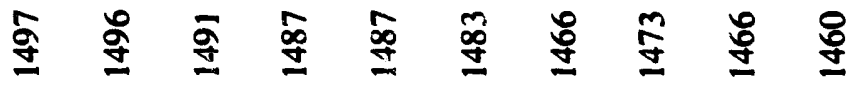

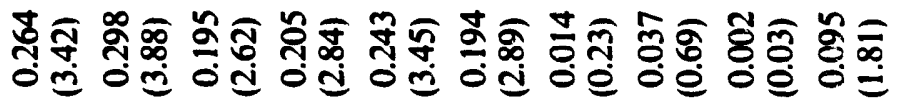

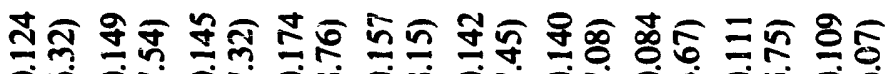

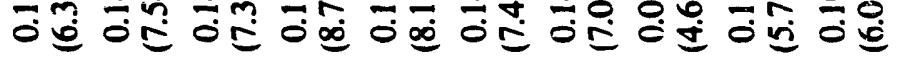

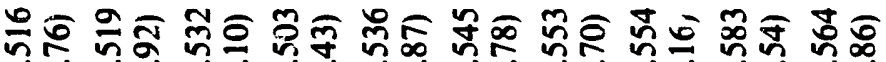

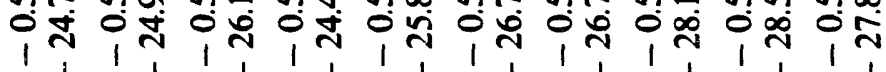

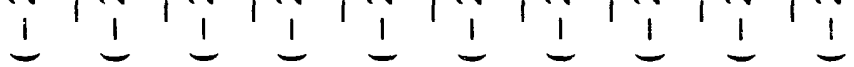

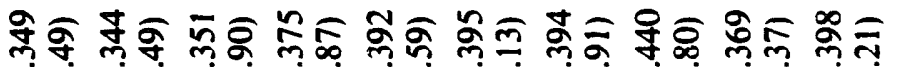

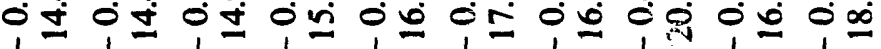

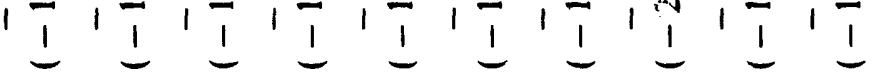

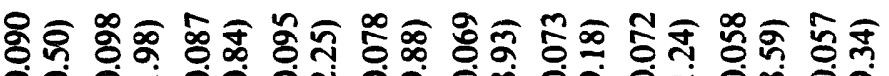

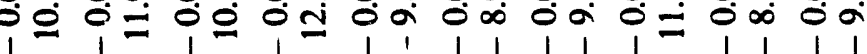

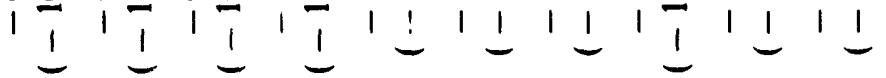

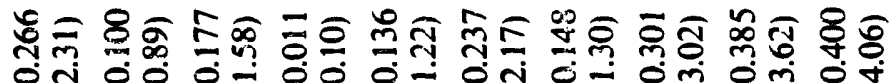

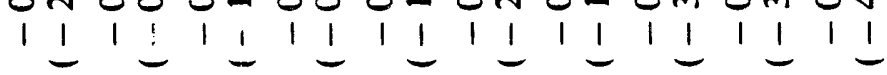

$n \infty \sim \infty a \cong \approx \approx$ 


\subsection{Relation of Black-Scholes put options to bid-ask spreads}

Our second testable hypothesis states that the effect of a stabilizing bid on dealers' losses can be modeled as a put option. In other words, the presence of price stabilization effectively truncates dealers' potential downside losses from adverse price movements. For each firm on each event date, put option values are calculated as described above and then used as proxies for stabilization in the cross-sectional regressions. Since these put options are 'written' by the stabilizer and held by the remaining dealers, spreads should narrow as the option value increases. Consequently, if price stabilization exists and affects the bid-ask spread, we predict that $\beta_{j t}$ should be negative immediately after the offer and should diminish in event time.

Estimates from this specification are plotted in fig. 2. Estimates of $\beta_{5 t}$ are negative and significant over the first ten days for all days except day 7 . Therefore, spreads are significantly related to the value of the put option written by the stajilizer, conditional on volume, the number of market makers, the price level, and variance.

The $(\log )$ difference between the market price and the floor price is an important component in the option value, and our two proxies for the valie of stabilization are highly correlated $\left(R^{2}=0.546\right.$ across all 45,237 observations). Therefore, tests using estimated put option values cannot be considered to be independent of those using $\ln$ (Bid price/Offer price).

The results presented in table 1 and figs. 1 and 2 are consistent with the presence of stabilizing bids during the first ten days trading. Of course, stabilizing activities are costly to the underwriter: prolonged stabilization is capitalintensive and in possible violaticn of the anti-manipulation provisions of the Securities Exchange Act. Therefore, we attribute the decay in the coefficients duririg this period to the suspension or abandonment of stabilization programs.

\subsection{Tests of robustness}

We first examine the robustness of our results using alternative specifications for the floor price. Initially, we assume that stabilization occurs at the offer price. However, constraining the floor price to be equal to the offer price maximizes the truncation of the price distribution. It is possible that if an issue is faring poorly, the underwriter will reduce the floor below the offer price. Ruud (1992) refers to this phenomena as 'partial price support'. Therefore, we estimate an alternative specification in which the support price equals the minimum of the offer price and the previous day's closing price. We use the previous day's closing price as an estimate of the floor price because of the regulatory constraint that the stabilizing bid cannot exceed the highest independent dealer's bid. The results are not significantly different from those reported above. 


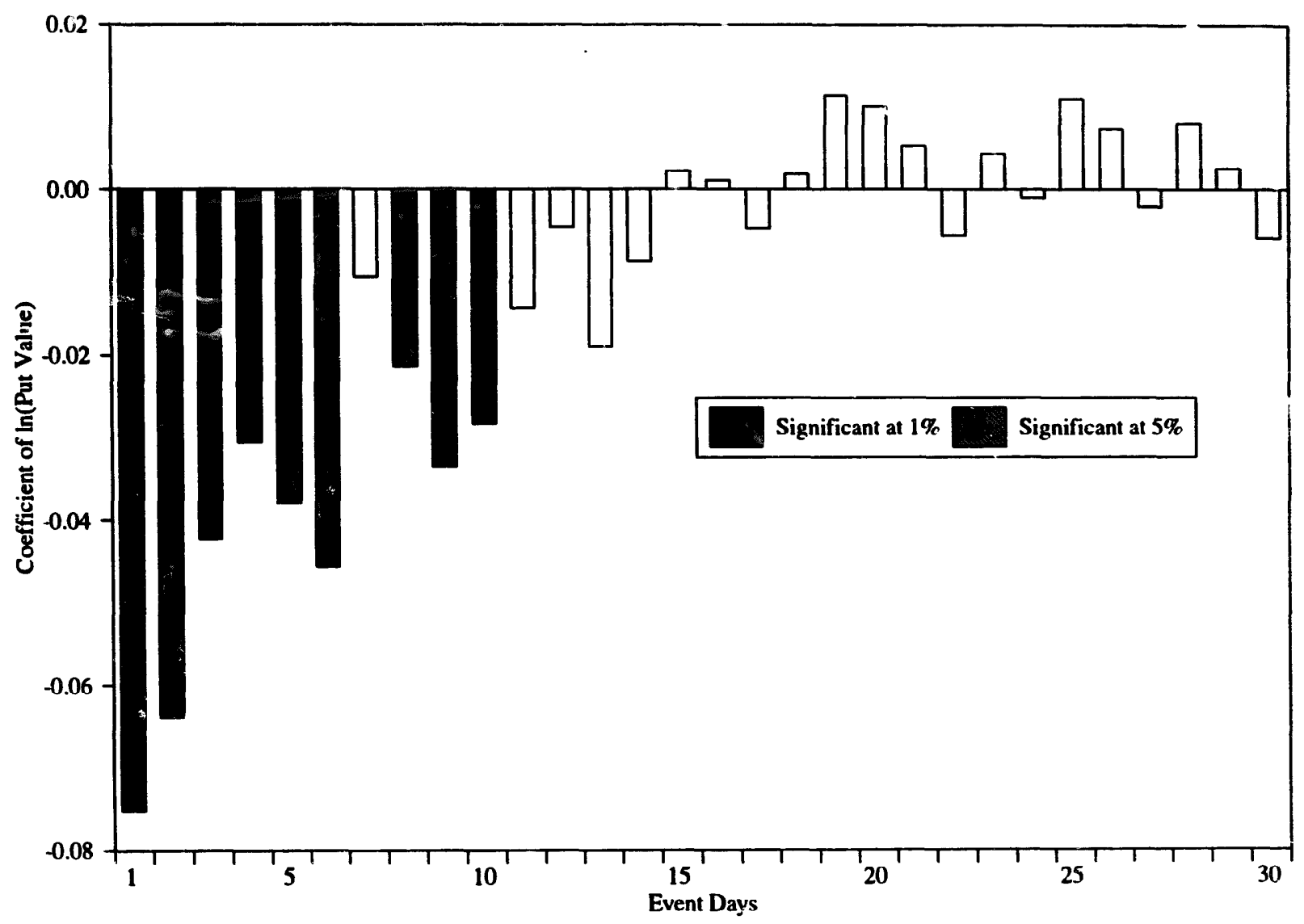

Fig. 2. This figure plots estimates of $\beta_{5 t}$, the coefficient linking the width of the bid-ask spread to the Black-Scholes option value of a European Put Option with $S=$ Stock price, $X=$ Offer price, $T=1, r_{f}=0$, and $\sigma=$ Volatility. The volatility measure is the rolling standard deviation computed as the standard deviation of daily returns of the first eleven days if the event day is less than or equal to 6 where event day $=1$ is the offer date of the IPO. If the event day is greater than 6 , then volatility is measured as the standard deviation of daily returns over the eleven-day window from five days before to five days after the event day. The coefficient is estimated from cross-sectional regressions of the form $\ln \left(\right.$ Relative spread) $=\alpha_{t}+\beta_{1 t} \ln$ (Volume) $+\beta_{2 t} \ln$ (Number of market makers) + $\beta_{3 t} \ln$ (Price) $+\beta_{4 t} \ln \left(\right.$ Volatility) $+\beta_{5 t} \ln$ (Put value) for $t=1$ to 30 . The sample consists of, 523 IPOs on NASDAQ between 1982 and 1987, identified from Investment Dealers' Digest. The number of observations for each event day cross-sectional regression varies from 1,466 to 1,502. All data, with the exception of the offer price, are frnm the CRSP NASDAQ tapes.

In addition, we examine two alternative interpretations for our findings. First, the CRSP tapes may record a market-determined ask price and a fixed stabilizer's bid. If the bid price is fixed and only the ask price varies, bid-ask spreads and midpoints are perfectly correlated. To rule out this mechanical alternative, we estimate the regressions using only those observations for which the best bid exceeds the offer price. Since stabilization is prohibited by law at values above the offer price, this subset should not contain stabilizing bids. The results for this subsample are not qualitatively different from the results for the full sample. 
The second interpretation is provided by Rock's (1986) model of adverse selection in IPOs. In this model, the proportion of informed traders in underpriced issues is greater than the proportion for overpriced issues. Thus, dealers in underpriced issues face a higher probability of trading against informed investors. Those dealers widen their quotes, generating a relation between $\ln (\mathrm{Bid}$ price/Offer price) and the width of the bid-ask spread.

There is little evidence, however, of positive abnormal returns beyond the initial trading day. Barry and Jennings (1992) demonstrate that underpricing is typically resolved at the first trade. Miller and Reilly (1987) provide evidence that any effects of Rock's adverse selection on bid-ask spreads are relevant only on the initial trading day. Therefore, the adverse information hypothesis should not affect our results beyond the first trading day.

\section{The effect of stabilization on reported returns}

We examine returns fo!lowing the hypothesized end of stabilization to determine whether the removal of stabilization leads to immediate price declines. We do so for two reasons. First, return-based evidence consistent with stabilization complements the spread results and increases the likelihood that the spread resuits aic attributable to stabilization. Second, though numerous studies examine returns for various IPO-based investment strategies, few (to our knowledge) explicitly recognize the potential impact of stabilization. It is therefore importari to document situations in which returns may be materially affected by stahilizing activities.

Since we cannot determine the actual date that stabilization ceases for each offer, we perform two tests based on different assumptions about when stabilization ends. Our tests employing bid-ask spreads indicate that stabilization has a significant effect on quoted spreads for roughly the first ten trading days; few coefficients associated with event days beyond that period are significant. In the first test we focus on returns immediately following day 10 . If stabilization is successful in maintaining prices above their intrinsic value, then price declines should, on average, occur at the end of stabilization, and such declines should occur only for those firms most likely io have experienced stabilization.

To capture differences in potential stabilization, we partition the sample into four groups, based upon the relation of the offer price to the day 10 market price:

Group 1: Issues with market prices more than $3 \%$ below the offer price (370 issues).

Group 2: Issues for which the market price is equal to or no more than $3 \%$ below the offer price (181 issues).

Group 3: Issues for which the market price exceeds the offer price by no more than $3 \%$ (160 issues). 
Grouip 4: Issues for which the market price exceeds the offer price by more than $3 \%$ (803 issues).

We choose the $3 \%$ boundary since it represents a typical bid-ask spread width for our sample. Movements beyond 3\% cannot be interpreted as movements from the bid to the ask or vice versa but must be due to changes in the posted quote.

Issues that have market prices less than or equal to the offer price on day 10 are partitioned into groups 1 and 2 . Since stabilization is a capital-intensive process, we hypothesize that issues which experience declines in value either will be too costly to stabilize for a long period of time or will not be stabilized at all. Therefore, issues in group 1 may contain some firms that were stabilized and others for which stabilization was either not attempted or proved unsustainable and was abandoned. Group 2, on the other hand, is comprised of those issues most likely to be stabilized since price declines are relatively small. In both groups, we expect that at least a portion of the issues will have been stabilized. Consequently, we anticipate subsequent price declines.

Since an underwriter is prohibited from stabilizing at a price above the offer price, stabilization is not a factor in groups 3 and 4 as of the tenth day. Therefore, we do not expect any significant price changes after the tenth day of trading when stabilization hypothetically ends. We include these issues as a way of contrasting return behavior after day 10 for stabilized and nonstabilized issues.

We measure the significance of returns after day 10 for these groups in a regression framework that accommodates potential cross-sectional return heteroskedasticity. The cumulative returns from the midpoint close of day 10 to the midpoint close of days 11 through 15 , and from the midpoint close of day 10 to the midpoint close of days 20,25 , and 30 , are regressed against four indicator variables, one for each group. There is no intercept in the model, so the coefficient of the $i$ th indicator variable is interpreted as the mean return for group $i$. White (1980) heteroskedastic-consistent estimates of standard errors are calculated.

The results, presented in table 2 , are consistent with the hypothesis that stabilization maintains prices above their equilibrium value. In the five days following day 10, the accumulated returns for groups 1 and 2 (those hypothesized most likely to be affected by stabilization) are $-1.39 \%$ and $-2.08 \%$, with associated White (1980) heteroskedastic-consistent $t$-statistics of -2.87 and -4.22 . Finding negative returns for group 2 that are larger (in absolute value) than those in group 1 is consistent with the 1940 SEC release, which recognizes that

stabilization is regarded as necessary only in the case of issues which are neither notable successes nor notable failures .... In the latter, where the 
Table 2

Cumulative average returns, from day - 10 to day 30, for four groups of IPOs. Group 1 consists of 370 issues that have a day -10 market price is lower than the offer price by at least $3 \%$. Group 2 consists of 181 issues that have a day - 10 market price that is equal to or no inore than $3 \%$ below the offer price. Group 3 consists of 169 issues that have a day - 10 market price that is greater than the offer price by no more than $3 \%$. Group 4 consists of 803 issues that have a day -10 market price that is greater than the offer price by more than $3 \%$. The sample consists of 1,523 IPOs issued on NASDAQ between 1982 and 1987, identified from Investment Dealers' Digest. All data, with the exception of the offer price, are from the CRSP NASDAQ tapes. White (1980) heteroskedasticconsistent $t$-statistics are in parentheses.

\begin{tabular}{|c|c|c|c|c|}
\hline Window & $\begin{array}{c}\text { Group } 1 \\
P_{10}< \\
0.97 * \text { Offer price }\end{array}$ & $\begin{array}{c}\text { Group } 2 \\
0.97 * \text { Offer price } \\
\leqslant P_{10} \leqslant \\
\text { Offer price }\end{array}$ & $\begin{array}{c}\text { Group } 3 \\
\text { Offer price } \\
<\mathrm{P}_{10} \leqslant \\
1.03 * \text { Offer price }\end{array}$ & $\begin{array}{c}\text { Group } 4 \\
\begin{array}{c}1.03 * \text { Offer price } \\
<\mathrm{P}_{10}\end{array}\end{array}$ \\
\hline$(10,11)$ & $\begin{array}{l}-0.78 \% \\
(-3.68)\end{array}$ & $\begin{array}{l}-0.57 \% \\
(-3.76)\end{array}$ & $\begin{array}{l}0.08 \% \\
(0.56)\end{array}$ & $\begin{array}{l}0.18 \% \\
(1.68)\end{array}$ \\
\hline$(10,12)$ & $\begin{array}{l}-0.99 \% \\
(-3.60)\end{array}$ & $\begin{array}{l}-0.95 \% \\
(-4.01)\end{array}$ & $\begin{array}{l}0.05 \% \\
(0.25)\end{array}$ & $\begin{array}{l}0.29 \% \\
(1.80)\end{array}$ \\
\hline$(10,13)$ & $\begin{array}{l}-1.05 \% \\
(-2.77)\end{array}$ & $\begin{array}{l}-1.04 \% \\
(-2.66)\end{array}$ & $\begin{array}{l}-0.13 \% \\
(-0.46)\end{array}$ & $\begin{array}{l}0.30 \% \\
(1.41)\end{array}$ \\
\hline$(10,14)$ & $\begin{array}{l}-1.23 \% \\
(-2.75)\end{array}$ & $\begin{array}{l}-1.55 \% \\
(-2.76)\end{array}$ & $\begin{array}{l}-0.24 \% \\
(-0.57)\end{array}$ & $\begin{array}{l}0.43 \% \\
(1.71)\end{array}$ \\
\hline$(10,15)$ & $\begin{array}{l}-1.39 \% \\
(-2.87)\end{array}$ & $\begin{array}{l}-2.08 \% \\
(-4.22)\end{array}$ & $\begin{array}{l}-0.54 \% \\
(-1.20)\end{array}$ & $\begin{array}{l}0.45 \% \\
(1.63)\end{array}$ \\
\hline$(10,20)$ & $\begin{array}{l}-1.50 \% \\
(-2.35)\end{array}$ & $\begin{array}{l}-3.05 \% \\
(-4.02)\end{array}$ & $\begin{array}{l}-0.49 \% \\
(-0.62)\end{array}$ & $\begin{array}{l}0.78 \% \\
(2.01)\end{array}$ \\
\hline$(10,25)$ & $\begin{array}{l}-1.48 \% \\
(-2.00)\end{array}$ & $\begin{array}{l}-3.22 \% \\
(-3.68)\end{array}$ & $\begin{array}{l}-0.20 \% \\
(-0.24)\end{array}$ & $\begin{array}{l}1.42 \% \\
(2.72)\end{array}$ \\
\hline$(10,3 v)$ & $\begin{array}{l}-1.85 \% \\
(-2.19)\end{array}$ & $\begin{array}{l}-3.11 \% \\
(-3.30)\end{array}$ & $\begin{array}{l}0.34 \% \\
\left(0 . .^{7} 4\right)\end{array}$ & $\begin{array}{l}1.87 \% \\
(3.25)\end{array}$ \\
\hline
\end{tabular}

selling pressure in the open market is too great, the underwriters cannot afford to support the market at or near the issues' original offering price. For the same reason, stabilizing cannot as a practical matter be used to stem a market or economic trend of any real significance [Securities Exchange Act Release 2446 (1940)].

In contrast, groups 3 and 4 , which are expected to be unaffected by stabilization, show no significant return behavior over the same interval. Accumulated returrs in the five days following day 10 are $-0.54 \%$ for group 3 and $0.45 \%$ for group 4 , with associated White (1980) heteroskedastic-consistent $t$-statistics of -1.20 and 1.63 , respectively. ${ }^{5}$ The conclusions are similar when net-of-market

${ }^{5}$ In a related test, Miller and Reilly (1987) document that issues that are overpriced on day 1 have significant negative returns twenty-one days after the offer. However, they provide no explanation for their findings. 
returns are used or contemporaneous market returns are included in the regression.

In the second test, we relax the assumption that stabilization ends on day 10 and allow stabilization to end at any time during the first fifteen days of trading. However, we assume that stabilization only occurs at the offer price. Therefore, observing a closing bid price below the offer price is interpreted as evidence that stabilization activities are terminated. We divide the total sample into two groups, Sample and Control. For the 772 'stabilized' issues (Sample), we define day $\tau$ as the first day that we observe a closing bid below the offer price. Next, we calculate cumbiative five-day returns from the closing bid on day $\tau$ to the closing bid on day $\tau+5$. For the 751 firms with no closing bids below the offer price during the rirst 15 days (Control), $\tau$ is randomly assigned from a distribution over days 1-15 that mimics the empirical distribution of $\tau$ for the 772 Sample firms, and five-day bid-io-bid returns are calculated.

To examine differences between firms that are classified as stabilized [at least one bid price less than the offer price (Sample)] and those that are not stabilized [bid prices never less than the offer price (Control)], we estimate a regression equation with the five-day $(\tau$ to $\tau+5)$ cumulative bid-to-bid returns as the dependent variable and a dummy variable equal to ane ior firms that are stabilized and zero for issues that are not. The intercept of this regression, which can be interpreted as the mean return for the control s.jmple, is $\mathbf{C} 76 \%$ [White $(1980)$ heteroskedastic-consistent i-statistic $=2.50$ ]. The coeffic $n$. ass $u$ ciated with the indicator variable, which is interpreted as the mear difference in cumulative returns between the two groups, is $-2.47 \%$ [White $(1980)$ heteroskedastic-consistent $t$-statistic $=-5.69]$. In cther words, issues that are hypothesized to have been stabilized have significant negative returns in the five days after stabilizing activities are posited to have ended.

These results are equivalent for the Sample and Control groups when using (i) different accumulation windows, (ii) a sample in which we delete all firms for which $\tau$ is equal to the first trading day (to differentiate the effect of stabilization from that documented by Miller and Reilly), (iii) net-of-market returns, (iv) the corresponding cumulative market return in the regression, (v) only those Control firms that experienced a price decline on day $\tau$, and (vi) combinations of these robustness tests.

Conditional upon observing whether the closing price is below the offer price, there is a predictable component in subsequent five-day returns. Regardless of the duration of stabilization or the level at which the underwriter stabilizes, we have indirect evidence that the withdrawal of stabilization significantly affects subsequent prices. These results are consistent with the findings of Ruud (1992), who demonstrates that asymmetries in the distribution of cumulative postoffering returns diminish in time.

The significance of the results of these two tests is surprising. We cannot observe which issues are stabilized or when stabilization on a particular issue is 
suspended. Consequently, our tests, which are predicated either on all stabilization endin ; on day 10 (as assumed in the first test) or on stabilization never occurring below the offer price (as assumed in the second test), are diminished in power. Nonetheless, we find a significant decline in the value of issues most likely to have been stabiize:, regardless of our assumptions about the timing and duration of stabilization.

Although significant declines in value occur for issues that are hypothesized to be stabilized, it is unlikely that an investor will be able to profitably exploit this knowiedge. Short selling is generally not feasible while the distribution of the offeris s open, and it is unlikely that syndicate members wouid aliow short positions during the first few days of traúing.

\section{\%. Conclusion}

We incirectly examine the effects of price stabilization on the market for new issues of common stock. For a sample of 1,523 NASDAQ initial public offerings issued between 1932 and 1987, we find evidence which suggests that stabilization significantly affects ruoted spreads. Quoted spreads are narrower when stabilization is expected to be most important, i.e., when transactions prices are close to the offer price during the first ten to fifteen trading days. We also provide evidence that stabilization has a tangible impact on prices; when stabilization is assumed to be suspended, market prices decline by approximately $2.5 \%$ over the following five days.

These results are important for three reasons. First, this study, along with Ruud (1992), demonstrates that stabilization has a significant impact on the after-market price of initial public offerings. Previous $;$ udies of returns to investors in IPOs have ignored the effect of stabilization on reported returns. Second, our results are of interest to those studying market structure as a competitive market for supplying liquidity services. We find that the value of a put ; tion implicitly written by a stabilizer is valued by dealers, and as a result, rompetition narrows spreads.

Finally, establishing that stabilization is common in the after-issue market for initial public offerings is important from a public policy perspective. Investors who engage in what they believe are open market transactions at prices determined by the unencumbered forces of supply and demand may find instead that they have purchased shares at artificially inflated prices and subsequently suffer losses. Perhaps m:ost surprising of all for investors is that this systematic and deliberate manipulation is completely legal under current securities law.

\section{Appendix}

The value of a stabilizing bid to nonstabilizing dealers can be derived using an options pricing framework. Copeland and Galai (1983) argue that for a dealer 
who sets a bid-ask quote, the expecied loss per transaction is proportional to

$$
L=\int_{A s k}^{\infty}(S-A s \dot{r}) f(S) \mathrm{d} S+\int_{0}^{B i d}(B i d-S) f(S) \mathrm{d} S,
$$

where $S$ is the subsequently revealed 'true' underlying asset value, governed by the distrib tion $f(S), A s k$ is the quoted ask price, and Bid is the quoted bid price. Due to the short lives of these options, ignoring discounting does not change the analysis.

In eq. (1), the first part of ine ioss is the opportunity loss of selling too low. In other words, the dealer has sold at an ask that is less than the subsequent true value. The latter half of the equation models the loss of buying too high. As an example of the downside issk associated with the dealer's position, co ssider the situation in which a dealer buys a share at the prevailing bid and subsequently discovers that the true, post-trade price has moved to some $S<B i d$. The dealer loses the difference between the bid price and the post-trade price. The bid and ask prices are set such that the expected downside losses due to the price declines, or forgone profits due to price increases, are exactly offset, under perfect competition, by revenues earned (via the bid-ask spread) when the price does not change.

As a result, the payoffs to the dealer are equivalent to those generated by a strategy in which the dealer writes a naked put with a strike price equal to the bid and writes a naked call with the strike equal to the ask. The loss per transaction, in this case, can be approximated by the value of a short straddle. [Copeland and Galai (1983), especially in section 5, provide details and limitations of the short straddle analogy. Due to the microstructure mechanisms of the NASDAQ system, a better analogy is the Copeland and Galai model for open quote intervals (section II.B). We do not present this model since it is expositionally more cumbersome, although it yields identical predictions.]

Assume that a dealer (who is not an underwriter or stabilizer) believes that there exists some maintained floor price; that is, there exists some price, $F$, at which a stabilizer is willing to buy some quantity of the stock from dealers. In this case, prospective losses to adverse price moves are truncated. Also assume that the dealer expects to be able to sell a fraction, $\Phi$, of his inventory to the stabilizer in the evcnt that the true asset value falls below the floor price. Consequently, the expected per-transaction loss in a market in which stabilization is present is proportional to

$$
\begin{aligned}
L_{S}= & \int_{A s k}^{\infty}(S-A s k) f(S) \mathrm{d} S+(1-\Phi) \int_{0}^{B i d}(B i d-S) f(S) \mathrm{d} S \\
& +\Phi \int_{F}^{B i d}(B i d-S) f(S) \mathrm{d} S+\Phi \int_{0}^{F}(B i d-F) j(S) \mathrm{d} S .
\end{aligned}
$$


The first ir egral ir eq. (2) is the same as in eq. (1), since issues that increase in value are not affecied by stabilization. The remainder of eq. (2) breaks down the expected downside losses given that the potential for stabilization exists. The second integrai is the expected loss for the proportion of shares that will not be bought by the stabilizer. In this case, the dealer bears the full weight of a price decline but only for a linited quantity, $(1-\Phi)$. For the remaining proportion of shares, the dealer faces a loss from two sources. If the true value, $S$, is greater than the floor but less than the dealer's bid, the dealer suffers a loss equal to the difference between the bid and $S$ since stabilization does not occur unless $S<F$. This loss is captured by the third integral. If, as shown in the last integral of eq. (2), the true value (S) is iess than the foor price, the dealer limits his loss by seiling to the stabilizer at a price $F$.

Under these scenarios, the change in the cost of providing liquidity services is borne by the stabilizer anc is proportional to

$$
\Delta L=L-L_{S}=\Phi \int_{0}^{F}(S \cdots F) f(S) \mathrm{d} S
$$

In short, the stabilizer has written, and the other clealers have received, a fraction of a put option with a strike price equal to the floor. Assuming the dealer market is competitive and a zero-profit constraint is imposed, then the value of the stabilizer's put should be incorporated into the per-transaction cost of providing liquidity, or the bid-ask spread.

Note that the above analysis is not predicated on observing actual stabilizing trades, but merely on the presence of a stabilizer and the belief by dealers that a stabilizer will be willing to absorb some fraction of their inventories at the floor price. Further, since the value of eq. (3) must be negative, there is a reduction in the expected cost to providing liquidity services even if $\Phi$ and $F$ are unknown to nonstabilizing dealers.

\section{References}

Barry, Christopher B. and Robert H. Jennings, 1992, The opening price performance of initial puttic offerings of common stock, Financial Management, forthcoming.

Conrad, Jennifer and Cathy M. Niden, 1991, Order flow, trading costs and corporate acquisition announcements, Working paper (University of North Carolina, Chapel Hill, NC and Unive rsity of Notre Dame, Southbend, IN).

Copeland, Thomas and Dan Galai, 1983, Information effects on the bid-ask spread, Journal of Finance 38, 1457-1460.

Hegde, Shantaram P. and Robert E. Miller, 1989, Market-making in initial public offerings: An empirical analysis, Journal of Financial and Quantitative Anaiysis 24, 75-90.

Hess, Alan and Peter A. Frost, 1982, Tests for price effects of new issues of seasoned securities, Journal of Finance 37, 11-26.

Ibbotson, Roger, 1975, Price performance of common stoct ne issues, Journal of Fir ancial Econoritics : 235-272. 
Jarrow, Robert and Andrew Rudd, 1983, Option pricing (Irwin, Homewood, IL).

Miller, Robert E. and Frank K. Reilly, 1987, An examination of mispricing, I turns, and uncertainty for initial public offerings, Financial Management 16, 33-38.

Rock, Kevin, 1986, Why new issues are underpriced, Journal of Financial Econonics 15, 187-212.

Ruud, Judith S., 1992, Underwriter price support and the IPO underpricing puzzle, Working paper (Federal Reserve Bank of New York, NY).

Stoll, Hans R., 1976, The pricing of underwritten offerings of listed common stocks and the compenustion of underwriters, Journal of Economics and business 28, 96-103.

White, Ha!bert, 1980, A heteroskedasticity-consistent covariance matrix estimator and a direct test for heteroskedasticity, Econometrica 48, 485-505. 